\begin{tabular}{|c|l|}
\hline Title & $\begin{array}{l}\text { Highly conserved linkage homology between birds and turtles: Bird and turtle chromosomes are precise counterparts of } \\
\text { each other }\end{array}$ \\
\hline Author(s) & $\begin{array}{l}\text { Matsuda, Yoichi; Nishida Umehara, Chizuko; Tarui, Hiroshi; Kuroiwa, A sato; Y amada, Kazuhiko; Isobe, Taku; A ndo, } \\
\text { Junko; Fujiwara, A tushi; Hirao, Y Ykako; Nishimura, O samu; Ishijima, Junko; Hay ashi, A kiko; Saito, Toshiyuki; } \\
\text { Murakami, Takahiro; Murakami, Y Yasunori; Kuratani, Shigeru; A gata, Kiy okazu }\end{array}$ \\
\hline Citation & $\begin{array}{l}\text { Chromosome Research, 13(6), 601-615 } \\
\text { https://doi.org/10.1007/S10577-005-0986-5 }\end{array}$ \\
\hline Issue Date & 2005-08 \\
\hline Doc URL & http://hdl.handle.net/2115/30315 \\
\hline Rights & The original publication is avail lable at www.springerlink.com \\
\hline Type & article (author version) \\
\hline File Information & CR13-6.pdf \\
\hline
\end{tabular}

Instructions for use 


\section{Highly conserved linkage homology between birds and turtles: bird and turtle chromosomes are precise counterparts of each other}

Yoichi Matsuda ${ }^{1,2 * *}$, Chizuko Nishida-Umehara ${ }^{1,2 *}$, Hiroshi Tarui ${ }^{3}$, Asato Kuroiwa ${ }^{1,2}$, Kazuhiko Yamada ${ }^{1}$, Taku Isobe ${ }^{1}$, Junko Ando ${ }^{1}$, Atushi Fujiwara ${ }^{4}$, Yukako Hirao ${ }^{3}$, Osamu Nishimura $^{3}$, Junko Ishijima ${ }^{1}$, Akiko Hayashi ${ }^{5}$, Toshiyuki Saito ${ }^{5}$, Takahiro Murakami ${ }^{1}$, Yasunori Murakami ${ }^{6}$, Shigeru Kuratani ${ }^{6}$ \& Kiyokazu Agata ${ }^{3}$

${ }^{1}$ Laboratory of Animal Cytogenetics, Division of Genome Dynamics, Creative Research Initiative "Sousei”, Hokkaido University, North 10 West 8, Kita-ku, Sapporo 060-0810, Japan; Tel: +81-11-706-2619; Fax: +81-11-736-6304; E-mail: yoimatsu@ees.hokudai.ac.jp;

${ }^{2}$ Division of Biological Sciences, Graduate School of Science, Hokkaido University, North 10 West 8, Kita-ku, Sapporo 060-0810, Japan;

${ }^{3}$ Laboratory for Evolutionary Regeneration Biology, RIKEN Center for Developmental Biology, 2-2-3 Minatojima-minamimachi, Chuo-ku, Kobe 650-0047, Japan;

${ }^{4}$ Immunology Section, National Research Institute of Aquaculture, Fisheries Research Agency, Tamaki, Mie 519-0423, Japan;

${ }^{5}$ Transcriptome Profiling Group, Research Center for Radiation Safety, National Institute of Radiological Sciences, 4-9-1 Anagawa, Inage-ku, Chiba 263-8555, Japan;

${ }^{6}$ Laboratory for Evolutionary Morphology, RIKEN Center for Developmental Biology, 2-2-3 Minatojima-minamimachi, Chuo-ku, Kobe 650-0047, Japan;

${ }^{\#}$ These authors contributed equally to this work.

* Correspondence

Short running title: Comparative chromosome maps of reptiles

Key words: turtle, snake, comparative mapping, conserved linkage homology, sex chromosome 


\section{Abstract}

The karyotypes of birds, turtles and snakes are characterized by two distinct chromosomal components, macrochromosomes and microchromosomes. This close karyological relationship between birds and reptiles has long been a topic of speculation among cytogenetists and evolutionary biologists; however, there is scarcely any evidence for orthology at the molecular level. To define the conserved chromosome synteny among humans, chickens and reptiles and the process of genome evolution in the amniotes, we constructed comparative cytogenetic maps of the Chinese soft-shelled turtle (Pelodiscus sinensis) and the Japanese four-striped rat snake (Elaphe quadrivirgata) using cDNA clones of reptile functional genes. Homology between the turtle and chicken chromosomes is highly conserved, with the six largest chromosomes being almost equivalent to each other. On the other hand, homology to chicken chromosomes is lower in the snake than in the turtle. Turtle chromosome $6 \mathrm{q}$ and snake chromosome $2 \mathrm{p}$ represent conserved synteny with the chicken $\mathrm{Z}$ chromosome. These results suggest that the avian and turtle genomes have been well conserved during the evolution of the Arcosauria. The avian and snake sex $\mathrm{Z}$ chromosomes were derived from different autosomes in a common ancestor, indicating that the causative genes of sex determination may be different between birds and snakes. 


\section{Introduction}

The karyotypes of birds, turtles and snakes are principally composed of two major chromosomal components, namely macrochromosomes and microchromosomes, which differ with respect to physical size, though the boundary between the two is not necessarily defined. Turtles have variable numbers of chromosomes, ranging from $2 \mathrm{n}=$ 26 to 68 (Ayres et al. 1969, Bickham \& Baker 1976, Bickham et al. 1983). The most common diploid number is around 50-52 in Emydidae, including 12-14 pairs of macrochromosomes and 12-14 pairs of microchromosomes, and 66 in Trionycidae, including 8-9 pairs of macrochromosomes and 24-25 pairs of microchromosomes (Bickham \& Baker 1976, Bickham et al. 1983). Similar karyotypes are also observed in birds. The bird karyotypes are remarkably uniform, and the modal number is around 80 , which consists of 7-10 pairs of macrochromosomes, including ZW sex chromosomes, and a large number of microchromosomes, though diploid chromosome numbers range from 50 in the Falconidae to over 100 in the Rallidae and Ramphastidae (Takagi \& Sasaki 1974, de Boer 1984, Belterman \& de Boer 1984, Sasaki et al. 1984). The first three pairs of macrochromosomes are outstandingly large, and the morphological similarities of the largest three chromosomes are shared by many of the species in diverse avian orders (Takagi \& Sasaki 1974). Based on the comparison of G-banding patterns between bird and turtle chromosomes, Takagi \& Sasaki (1974) suggested that the largest three pairs might have been transmitted without many structural changes from a common ancestor of birds and turtles. The range of karyotypic variation is very narrow in snakes. The most common diploid number of snakes is $2 n=36$, which consists of eight pairs of 
macrochromosomes and ten pairs of microchromosomes (Beçak et al. 1964, Beçak \& Beçak 1969, Singh 1972). The close karyological relationship between birds and reptiles has long been at topic of speculation among cytogenetists and evolutionary biologists; however, there is hardly any evidence to confirm this similarity at the molecular level. Graves \& Shetty (2000) demonstrated by comparative chromosome painting of the turtle (Chelodina longicollis) that chicken chromosome 4 painted the fourth largest pair of autosomes and the short arm of chromosome 7/8 in the turtle. The chicken $\mathrm{Z}$ chromosome was equivalent to the fifth-largest autosomal pair of the turtle (Graves \& Shetty 2001). These results suggest that chromosome homology might have been preserved between turtles and birds; however, gene-based conserved synteny between the two genera has not been verified by comparative gene mapping.

As detailed physical and genetic linkage maps of the chicken have been constructed, extensive chromosome homology between the chicken and human genomes (about 100 conserved syntenic segments) has been revealed (Groenen et al., 2000, Schmid et al. 2000). The comparative maps of functional genes between chicken and mammalian species provide new insights into the evolution of vertebrate genomes (Burt et al. 1995, 1999, Nanda et al. 1999, 2000, Groenen et al. 2000, Schmid et al. 2000, Burt 2002). This approach makes it possible to compare chromosomes between species belonging to different classes or phyla, but reptiles have not been the subject of comparative mapping because there are almost no DNA probes for functional genes in reptiles. Comparative mapping between birds and reptiles would provide more detailed information about the evolution of the amniotes, which has not been studied yet. Partial sequencing of a large 
number of cDNAs to develop expressed sequence tags (ESTs) facilitates gene discovery using the EST database (dbEST), and ESTs provide a ready source of DNA probes for comparative gene mapping between any species. Orthologs are homologous genes from different species that evolved from a common ancestral gene and normally retain the same function during evolution. The identification of orthologous genes from reptile EST clones facilitates the direct comparison of human, avian and reptilian genomes by comparative gene mapping.

In this study we constructed cDNA libraries from the brain tissue and the 14-day-old whole embryos of the Chinese soft-shelled turtle and from the brain tissue of the Japanese four-striped rat snake. We isolated a large number of cDNA clones at random from the turtle and snake cDNA libraries, determined their partial sequences, and then searched for orthologs from the reptilian EST clones for comparative gene mapping. Here we address the relationships of genome organization between chicken and two reptilian species by constructing their comparative cytogenetic maps with the EST clones.

\section{Materials and Methods}

Specimen

Adult females and embryos of the Chinese soft-shelled turtle (Pelodiscus sinensis, Trionychidae, Testudinata) were purchased from a breeding farm in Japan, and used for constructing cDNA libraries and chromosome preparations. Wild individuals of the Japanese four-striped rat snake (Elaphe quadrivirgata, Colubridae, Ophidia) were 
captured in the field in Japan and used for the experiments.

\section{Construction of cDNA libraries, DNA sequencing and database analysis}

The sources of RNA used for constructing cDNA libraries were the brain tissue of an adult female and whole 14-day embryos for the turtle, and the brain tissues of eighteen adult male and female individuals for the snake. Poly (A) mRNAs were isolated from the fresh tissues, and cloned into the $\lambda$ uni-ZAP vector (Stratagene) using standard protocols. Lambda uni-ZAP clones were converted into pBluescript SK (+) clones, and transformed into XL1-Blue bacterial cells (Stratagene). Colonies were randomly picked and transferred into 96-well plates using the 'Q' Pix (GENETIX). The clones were grown overnight, and the plasmid DNAs were prepared using MultiScreen-NA and FB plates (Millipore, Bedford, MA). Sequencing reactions were performed with dideoxy dye-labeled terminator using SK primer according to the manufacturer's protocol (Applied Biosystems), and the nucleotide sequences were determined using an ABI PRISM3700 DNA Analyzer (Applied Biosystems). The nucleotide sequence comparisons versus the National Center for Biotechnology Information (NCBI) database were performed using the blastx program. Individual ESTs were translated in all reading frames and compared against the NCBI "non-redundant" nucleotide and/or peptide sequence database (http://www.ncbi.nlm.nih.gov/blast/Blast.cgi?). All the EST clones mapped to turtle and snake chromosomes were deposited in DNA Data Bank of Japan (DDBJ; http://www.ddbj.nig.ac.jp/Welcome.html). 


\section{Cell culture, chromosome preparation and FISH}

Preparation of R-banded chromosomes and fluorescence in-situ hybridization (FISH) were performed as described previously (Matsuda \& Chapman 1995, Suzuki et al. 1999). The fibroblast cells collected from the embryos of the turtle and the heart tissues of the female snakes were cultured in 199 medium supplemented with $15 \%$ fetal bovine serum at $26^{\circ} \mathrm{C}$ in $5 \% \mathrm{CO}_{2}$. 5-bromodeoxyuridine (BrdU) was incorporated during the late replication stage for differential staining. The cells were harvested after colcemid treatment for $1 \mathrm{~h}$, suspended in $0.075 \mathrm{M} \mathrm{KCl}$, fixed in 3:1 methanol : acetic acid three times, then dropped on glass slides and air-dried. R-banded chromosomes were obtained by exposure of chromosome slides to UV light after staining with Hoechst 33258. Slides were kept at $-80^{\circ} \mathrm{C}$ until use.

The cDNA fragments amplified from the EST clones by PCR were used as probes for FISH mapping. The inserts were amplified using Insert Check Ready Blue (Toyobo) that included universal M13 P7 and M13 P8 primers. DNA amplification was performed in a total reaction volume of $100 \mu 1$ containing $100 \mathrm{ng}$ of plasmid as a template. PCR products were electrophoresed on a $1 \%$ agarose gel, recovered using Sprec-DNA Recovery Filter Tubes (Takara Biomedical), and purified according to the manufacturer's instructions.

The DNA probes were labeled by nick translation with biotin-16-dUTP (Roche Diagnostics) using a standard protocol. The hybridized cDNA probes were reacted with goat anti-biotin antibodies (Vector Laboratories), and then stained with fluoresceinated donkey anti-goat IgG (Nordic Immunology). The slides were stained with $0.50 \mu \mathrm{g} / \mathrm{ml}$ 
propidium iodide for observation. FISH images were observed under a Nikon fluorescence microscope using Nikon filter sets B-2A and UV-2A. Kodak Ektachrome ASA100 films were used for microphotography.

Molecular cloning of reptilian homologs of chicken Z-linked genes

The turtle and snake homologs of the chicken Z-linked genes, DMRT1, ACO1 and CHD1, were molecularly cloned by RT-PCR. Total RNAs were extracted from testes of the turtle and the snake using Trizol (Invitrogen). The cDNAs were synthesized using SuperScript II Rnase H(-) Reverse Transcriptase (Invitrogen). Various sets of PCR primers were synthesized based on the conserved regions of the three genes. The degenerate primer pairs used in the RT-PCR reactions were as follows: Primers for DMRT1: F2, 5'-GCA GCG GGT GAT GGC NGC NCA GGT-3’; R1, 5’-GCC AGA ATC TTG ACT GCT GGG YGG YGA -3'. Primers for ACO1:F1, 5'-GAC AGY TTR CAR AAG AAT CAR GAY-3’; R1, 5'-CCY TTR AAT CCT TGC TTN GYT CC-3’; F2, 5'-GTG CTC ACY RTN ACN AAG CAC CT-3’; R2, 5’-AGG TCT CCC TGN GTD ATN GCY TC-3'. Primers for CHD1:F1, 5’-CTC CAG AAG ATG TGG AAT ATT ATA AYT GC -3’; R1, 5’-TAT TGT TTT NCC NAG NCC CAT TTC A-3’; F2, 5’-TGG TGC AAA GGN AAT AGT TGY ATH C-3’; R2, 5’-AGY TCY TTG TGN AGR CTT GCA TAA CC-3’; F3, 5’-TGT AAC CAT TGC TAC CTC ATT AAR CC-3’; R3, 5’-AGA TCA TTY TGT GGA TTC CAR TCN GAA TCR-3’. Amplification of the fragments was achieved using the Ex Taq system (Takara Biomedical). The PCR conditions were an initial denaturation at $94^{\circ} \mathrm{C}$ for $2 \mathrm{~min}$, followed by 35 cycles of $94^{\circ} \mathrm{C}$ for $30 \mathrm{~s}, 60^{\circ} \mathrm{C}$ for $30 \mathrm{~s}$ and $72^{\circ} \mathrm{C}$ for $30 \mathrm{~s}$; 
and finally $72^{\circ} \mathrm{C}$ for $5 \mathrm{~min}$. The PCR products with more than one band were separately isolated and subcloned using the pGEM-T Easy Vector System (Promega). The 5'-UTR of the DMRT1 gene was amplified using the 5' RACE system version 2.0 (Invitrogen). The two pairs of primers for the ACO1 gene, F1/R1 and F2/R2, amplified 794 bp and 797 bp products, respectively. The three pairs of primers for the CHD1 gene, F1/R1, F2/R2, and F3/R3, amplified 443 bp, 584 bp and 401 bp products, respectively. The nucleotide sequences of the cDNA clones were determined using an ABI PRISM3100 DNA Analyzer (Applied Biosystems) after performing the sequencing reaction with dideoxy dye-labeled terminator using SK primer according to the manufacturer's protocol.

\section{Results}

The chromosome number of the Chinese soft-shelled turtle was 66 with nine pairs of macrochromosomes and 24 pairs of microchromosomes, which was quite similar to that of the chicken (Figure 1a and b). The present study confirmed the previous data reported by Sato \& Ota (2001). The Japanese four-striped rat snake had $2 n=36$, with eight pairs of macrochromosomes, including differentiated $\mathrm{Z}$ and $\mathrm{W}$ chromosomes, and 10 pairs of microchromosomes (Figure 1c). The submetacentric $\mathrm{W}$ chromosomes might have resulted from a pericentric inversion of the metacentric $\mathrm{Z}$ chromosome followed by partial deletion.

We isolated 382 and 1,150 non-redundant EST clones from the cDNA libraries constructed from the adult brain and the 14-day-old embryos of the Chinese soft-shelled 
turtle, respectively. Two thousand ninety-seven non-redundant ESTs were also isolated from the brain cDNA library of the Japanese four-striped rat snake. EST clones with blastx scores less than $1 \mathrm{e}^{-45}$ were classified as putative reptile homologs of human genes in this study. Fifty-nine turtle and 52 snake homologs of human orthologous genes were carefully selected by eliminating family genes (Tables 1 and 2), and cytogenetically localized to chromosomes by FISH (Figure 2).

Forty turtle homologs were specifically localized to the six largest pairs of macrochromosomes, and the remaining 19 homolog clones were localized to chromosomes smaller than chromosome 6 (the microchromosomes)(Table 1). Ten conserved segments, to which two or more genes were mapped, were identified between the human chromosomes and turtle chromosomes. Chromosome homologies between chicken and the turtle were examined using the current information on the human-chicken comparative map (Schmid et al. 2000, Burt 2002) (Figure 3). Twelve out of 13 clones located on the Chinese soft-shelled turtle chromosome 1 (Pelodiscus sinensis chromosome: PSI) were localized to seven regions homologous to human chromosomes (Homo sapiens chromosome: HSA) 1q, 6p, 12p, 12q, 21q, 22q and Xp, where conserved synteny has been also identified in chicken chromosome 1 (Gallus gallus chromosome: GGA). Seven genes on PSI2 were localized to regions homologous to HSA1q, 3p, 7p, 7q, $8 q$ and 22q, which are orthologous to GGA2. Five genes on PSI3 were localized to the conserved regions of GGA3 homologous to HSA1q, 2p and 6q. Four genes on PSI4 and five genes on PSI5 were localized to regions conserved between GGA4 and HSA4p and 4q, and between GGA5 and HSA14q and 15q, respectively. The locations of the turtle 
homologs on chicken chromosomes were searched using the annotation database of the first draft chicken genome assembly, Ensembl Chicken Web Server (URL: http://www.ensembl.org/Gallus_gallus/) (International Chicken Genome Sequencing Consortium 2004, Wallis et al. 2004). Forty-six (78.0\%) out of 59 mapped genes were physically localized to chicken chromosomes based on the genome sequences. Chromosomal locations were directly compared between chicken and the turtle for twenty-eight (82.4\%) of 34 genes mapped in turtle chromosomes 1-5. The five largest chromosomes were equivalent between chicken and the turtle for 26 of these 28 genes (the exceptions were PPP1CC on GGA15 and BAZ1B on GGA19). It has been revealed that the biarmed GGA4 was derived from a centric fusion between the ancestral types of acrocentric chromosome 4 and a microchromosome (Shetty et al. 1999, Nishida-Umehara et al. unpublished). The homology to HSAXq, which corresponds to the p arm of GGA4, was observed in a microchromosome in P. sinensis, indicating that that PSI4 retained the ancestral type of chromosome 4 (Table 1$)$.

Forty-six snake homologs of human genes were localized to the eight largest pairs of macrochromosomes, including the sex $\mathrm{Z}$ chromosome, the remaining six homologs being localized to chromosomes smaller than chromosome 7 (Table 2). Eleven conserved segments were identified between the human chromosomes and snake chromosomes (Figure 4). Twenty-five (54.3\%) out of the 46 genes mapped on the snake chromosomes 1-7 and Z were localized directly to chicken chromosomes by the search with Ensembl. Five snake homologs, EPRS (HSA1q41-q42), XPO1 (HSA2p16) MGC15407 (HSA2p16.2), MDN1 (HSA6q15) and QKI (HSA6q26-q27), mapped on the short arm of 
the Japanese four-striped rat snake chromosome (Elaphe quadrivirgata chromosome: EQU) 1 were identified on GGA3, which also has conserved synteny with HSA1q, 2p and 6q. Three genes on EQU1q, GPHN (HSA14q23.3-q24.1), DNCH1 (HSA14q32.3-qter) and ISYNA1 (HSA19p13.11) were localized to GGA5, which has been found to be homologous to HSA14q but not to HSA19p. The short and long arms of EQU2 showed homology to GGAZ and GGA13, respectively. The homologies to HSA9p and HSA5q are shared between EQU2p and GGAZ and between EQU2q and GGA13. The short and long arms of EQU3 were homologous to GGA2 and GGA26, respectively. Conserved synteny to HSA18q and HSA1p was also found in GGA2 and GGA26, respectively. EQU4p and EQU4q showed homology to HSAXp and HSA21q, respectively, which are included in the syntenic region with GGA1. EQU5q, which corresponded to HSA3q and HSA10q, had homology to two chicken chromosomes, GGA6 and GGA9. The long arm of EQU6 was homologous to GGA 1, which has conserved homology with HSA22q. Conserved synteny with HSA4q was found on GGA4 and EQU7q. Two genes, TAX1BP1 (HSA7p15) and WAC (HSA10), mapped on EQUZ were not located on the chicken sex Z chromosome, and were instead localized to chicken autosome GGA2, which also has conserved synteny with HSA7p and HSA10. Twenty-four snake genes were localized to chicken chromosomes that show conserved synteny with the human chromosomes in which their human homologs are located; the one exceptional gene was ISYNA1 (HSA19p13.11). The highly conserved linkage homologies were also found between the snake and chicken chromosomes. Each of the arms of the largest five biarmed snake chromosomes corresponded to one chicken 
chromosome; however, the chromosomal correspondence identified between the turtle and chicken was not found between the snake and chicken.

No sex chromosomes were identified morphologically in the Chinese soft-shelled turtle (Figure 1). Six genes located on HSA5q, 9p, 9q and 18q, which are homologous to chicken Z chromosome, were localized to PSI6 (Figure 5). Three turtle homologs of chicken Z-linked genes, DMRT1, ACO1 and CHD1 (an EST clone of CHD1 was also identified in this study), which were cloned from adult testis of the turtle by RT-PCR, were also localized to PSI6, indicating that PSI6 is equivalent to the chicken Z chromosome. On the other hand, two genes located on HSA10p and 7p, in which no homology to the chicken $\mathrm{Z}$ chromosome has been found, were localized to the snake sex $\mathrm{Z}$ chromosome that is homologous to the short arm of GGA2. The snake EST clones of eight genes located on HSA 5p, $5 q$ and $9 p$ and three snake homologs of the chicken Z-linked genes DMRT1, ACO1 and CHD1 cloned by RT-PCR were localized to EQU2 (Figure 5), indicating that the short arm of EQU2 corresponds to the chicken Z chromosome.

The 1164 bp cDNA fragment of the turtle DMRT1 gene (Accession No. AB179697) and the 1235 bp cDNA fragment of the snake DMRT1 (AB179698) had 82.6\% (683/827 bp) and $74.8 \%$ (624/834 bp) nucleotide identities with the equivalent region in the chicken DMRT1 cDNA fragment (AF211349), respectively (data not shown). The amino acid sequences of the turtle and snake DMRT1 genes showed 82.9\% (228/275 AA) and 75.5\% (209/277 AA) identities with the equivalent region in the chicken DMRT1 (Figure 6). In both cases, $100 \%$ identity was found in the DM domain with the chicken gene at 
the amino acid level. The nucleotide and amino acid sequences of the turtle and snake DMRT1 genes were conserved between chicken and the two reptile species, and the identity of the turtle DMRT1 gene was higher than that of the snake. The concatenated 1122 bp (AB185397) and 1122 bp (AB185398) cDNA fragments of the turtle and snake ACO1 genes showed 81.7\% (917/1122 bp) and 79.0\% (886/1122 bp) nucleotide identities, and 88.8\% (332/374 AA) and 88.0\% (329/374 AA) identities at amino acid level with the chicken ACO1 fragment (D16150), respectively (data not shown). The nucleotide sequence identities of the CHD1 cDNA fragments of the turtle (915 bp, AB185401 and 345 bp, AB185402) and snake (941 bp, AB185399 and 345 bp, AB185400), which were separately cloned fragments of the full cDNA sequences, were 89.7\% (1130/1260 bp) (88.6\%, 811/915 bp and 92.5\%, 319/345 bp) and 84.4\% (1086/1286 bp) (84.0\%, 790/941 bp and 85.5\%, 296/345 bp) with the equivalent region in the chicken CHD1Z fragment (AF004397), respectively (data not shown). The amino acid identities were $98.1 \%$ (411/419 AA) (97.4\%, 297/305 AA and 100\%, 114/114 AA) and 97.4\% (417/428 AA) (97.5\%, 306/314 AA and 97.4\%, 111/114 AA) for the turtle-chicken and snake-chicken comparisons, respectively. The nucleotide sequence identities of the two reptile genes to their chicken homologs were higher in the turtle than the snake.

\section{Discussion}

The molecular time scale of vertebrate evolution indicates that the earliest ancestors of mammals (synapsids) and birds (diapsids) first appeared in the Carboniferous period 
around 310 million years ago (MYA) (Kumar \& Hedges 1998). Mitochondrial DNA comparisons suggest that birds are most closely related to crocodilians, and the divergence between the two lineages is estimated to have occurred at 210-250 MYA (Janke \& Arnason 1997, Kumar \& Hedges 1998, Hedges \& Poling 1999, Kumazawa \& Nishida 1999, Mannen \& Li 1999). The phylogenetic position of turtles relative to other amniotes has remained uncertain for some time. The traditional placement of turtles was separate from the diapsid reptiles, as the sole descendants of a presumably primitive anapsid reptilian group. A recently proposed molecular phylogeny, which was estimated from the nucleotide sequences of complete mitochondrial genomes and the nuclear genes, indicates that turtles should be grouped in the Archosauria with birds and crocodilians, and lizards and snakes can be classified into a different clade (the Lepidosauria) (Caspers et al. 1996, Zardoya \& Meyer 1998, Hedges \& Poling 1999, Kumazawa \& Nishida 1999, Mannen \& Li 1999, Mindel et al. 1999, Cao et al. 2000, Iwabe et al. 2005). Closely related species are generally expected to share more conserved segments than distantly related species; however, this rule is not always applicable between chicken and the Chinese soft-shelled turtle and between human and mouse. Based on the comparative mapping data of human, mouse and chicken, the organization of the human genome is suggested to be closer to that of the chicken, with 72 predicted chromosome rearrangements (ranging from 44 to 93), which is much less than the at least 171 rearrangements between mouse and human (Burt et al. 1999). The present study reveals extensive chromosomal homologies between chicken and the Chinese soft-shelled turtle, although the two lineages diverged from the common ancestor more than 210 MYA. By 
contrast, chromosomal rearrangements have occurred more frequently between mouse and human than between chicken and the turtle (Carver \& Stubbs 1997, Burt et al. 1999, Schmid et al. 2000, Burt 2002,), although the lineage of human and mouse diverged more recently (80-90 MYA) (Hasegawa et al. 2003). Our data suggest that the karyotypes of birds and turtles, consisting of few macrochromosomes and a large number of microchromosomes, have remained relatively stable and conserved, and thus inter- and intrachromosomal rearrangements have hardly occurred in the two lineages after divergence from the common ancestor. A higher frequency of interchromosomal rearrangements, which occurred between macrochromosomes and also between macroand microchromosomes, led to the karyotype with several large-sized macrochromosomes and fewer numbers of microchromosomes in the lineage of snakes. The higher conserved synteny in the chicken-turtle comparison than the chicken-snake comparison supports the proposed molecular phylogenetic relationships among the three genera (Zardoya \& Meyer 1998, Cao et al. 2000).

Reptiles exhibit different features of sex determination from birds and mammals. In all snakes, most lizards and a minority of turtles, sex is determined by genes carried on sex chromosomes, according to male $(\mathrm{XX} / \mathrm{XY})$ or female $(\mathrm{ZZ} / \mathrm{ZW})$ heterogamety. Only the ZZ/ZW mechanism exists in snakes (Beçak et al. 1964, Beçak \& Beçak 1969, Singh 1972, Jones \& Singh 1985), whereas both XX/XY and ZZ/ZW mechanisms have been found in lizards and turtles (Bull et al. 1974, King \& Rofe 1976, Carr \& Bickham 1981). In contrast to the genotypic (GSD) or chromosomal sex determination (CSD), temperature-dependent sex determination (TSD) is widespread in reptiles (Pieau et al. 
1999, Pieau \& Dorizzi 2004,). The mechanisms of sex determination and the primary factors of its complexity in birds and reptiles remain unknown (Sarre et al. 2004, Smith \& Sinclair 2004). In the Chinese soft-shelled turtle, which belongs to the Triionychidae, sex is genetically determined, not temperature-dependent (personal communication by $\mathrm{H}$. Ota), although no heteromorphic sex chromosomes have been identified. The extensive conservation of synteny between the chicken $\mathrm{Z}$ chromosome and human chromosomes 5 and 9 is demonstrated by comparative mapping of chicken homologs of human genes (Nanda et al. 1999, 2000, Schmid et al. 2000, Burt 2002). On the other hand, chicken homologs of the human X-linked genes have been localized to chicken chromosomes 1 and 4 (Schmid et al. 2000, Burt 2002, Kohn et al. 2004), indicating that the avian sex Z chromosome and the mammalian sex $\mathrm{X}$ chromosome have evolved independently from different autosomes of a common ancestor. Although sex chromosomes are not discriminated morphologically from other autosomes in the Chinese soft-shelled turtle, chromosome 6 has extensive conserved linkage homology to human chromosomes 5 and 9, and the three chicken Z-linked genes are localized to chromosome 6 . These results suggest that the ancestral chromosomes of the avian sex $\mathrm{Z}$ chromosomes have been conserved as an autosome in the turtle genome for around 230-240 MY (Hedges \& Poling 1999, Kumazawa \& Nishida 1999).

The DMRT1 gene, which encodes a putative transcription factor with a conserved $\mathrm{DM}(\underline{\mathrm{d}} s x$ and $\underline{m a b}-3)$ domain, is located in the minimal region of human chromosome 9p that is deleted in XY male-to-female sex reversal patients (Raymond et al. 1999). The structural homology between vertebrate and invertebrate DMRT1 genes and their 
remarkable capacity to complement their function across different phyla indicate that the DMRT1 genes are conserved forms of an ancient sexual regulator (Raymond et al. 1998). The chicken DMRT1 homolog is located on the Z chromosome, and therefore DMRT1 is thought to be a strong candidate for an avian sex determining gene (Nanda et al. 2000, Shetty et al. 2002). The chromosomal location of the DMRT1 homolog on the snake chromosome 2 and the discordance between the chicken and snake sex $\mathrm{Z}$ chromosomes suggest that the critical sex determining genes may be different between birds and snakes, and thus the mechanisms of sex determination have evolved independently in the two genera.

The present approach of comparative mapping using an extensive number of ESTs is a new strategy to investigate chromosome homologies between reptiles and birds. The disposition of conserved chromosome segments among reptiles, birds and mammals provides clues for clarifying the phylogenetic hierarchy of genome evolution in vertebrates.

\section{Acknowledgements}

We are very grateful to Dr. David Burt, Roslin Institute, UK, for valuable suggestions and critical reading of the manuscript. This work was supported by Grants-in-Aid for Scientific Research (No. 11NP0201, No. 15370001 and No. 16086201) from the Ministry of Education, Culture, Sports, Science and Technology in Japan. 


\section{References}

Ayres M, Sampaio MM, Barros RMS, Dias LB, Cunha OR (1969) A karyological study of turtles from the Brazilian Amazon Region. Cytogenetics 8: 401-409.

Beçak W, Beçak ML (1969) Cytotaxonomy and chromosomal evolution in Serpentes. Cytogenetics 8: 247-262.

Beçak W, Beçak ML, Nazareth HRS, Ohno S (1964) Close karyological kinship between the reptilian suborder Serpentes and the class Aves. Chromosoma 15: 606-617.

Belterman RHR, de Boer LEM. (1984) A karyological study of 55 species of birds, including karyotypes of 39 species new to cytology. Genetica 65: 39-82.

Bickham JW, Baker RJ (1976) Chromosome homology and evolution of emydid turtles. Chromosoma 54: 201-219.

Bickham JW, Bull JJ, Legler JM (1983) Karyotypes and evolutionary relationships of trinychoid turtles. Cytologia 48: 177-183.

Bull JJ, Moon RG, Legler, JM (1974) Male heterogamety in kinosternid turtles (genus Staurotypus). Cytogenet Cell Genet 13: 419-425.

Burt DW (2002) Origin and evolution of avian microchromosomes. Cytogenet Genome Res 96: 97-112.

Burt DW, Bumstead N, Bitgood JJ, Ponce de Leon FA, Crittenden LB (1995) Chicken genome mapping: a new era in avian genetics. Trends Genet 11: 190-194.

Burt, DW, Bruley C, Dunn IC, Jones CT, Ramage A, Law AS, Morrice DR, Paton IR, Smith J, Windsor D, Sazanov A, Frles R, Waddington D (1999) The dynamics of 
chromosome evolution in birds and mammals. Nature 402: 411-413.

Cao Y, Sorenson MD, Kumazawa Y, Mindell DP, Hasegawa M (2000) Phylogenetic position of turtles among amniotes: evidence from mitochondrial and nuclear genes. Gene 259: 139-148.

Carr JL, Bickham JW (1981) Sex chromosomes of the Asian black pond turtle, Siebenrockiella crassicollis (Testudines: Emydidae). Cytogenet Cell Genet 31: 178-183.

Carver EA, Stubbs L (1997) Zooming in on the human-mouse comparative map: genome conservation re-examined on a high-resolution scale. Genome Res 7: 1123-1137.

Caspers G-J, Reinders G-J, Leunissen JAM, Wattel J, de Jong WW (1996) Protein sequences indicate that turtles branched off from the amniote tree after mammals. $J$ Mol Evol 42: 580-586.

De Boer LEM (1984) New developments in vertebrate cytotaxonomy VIII. A current list of references on avian karyology. Genetica 65: 3-37.

Graves JAM, Shetty S (2000) Comparative genomics of vertebrates and the evolution of sex chromosomes. In: Clark MS (ed) Comparative Genomics. Kluwer Academic Publishers, Boston, Dordrecht, London, pp153-205.

Graves JAM, Shetty S (2001) Sex from W to Z: Evolution of vertebrate sex chromosomes and sex determining genes. J Exp Zool 290: 449-462.

Groenen MAM, Cheng HH, Bumstead N, Benkel BF, Briles WE, Burke T, Burt DW, Crittenden LB, Dodgson J, Hillel J, Lamont S, Ponce de Leon A, Soller M, Takahashi H, Vignal A (2000) A consensus linkage map of the chicken genome. 
Genome Res 10: 137-147.

Hasegawa M, Thorne JL, Kishino H (2003) Time scale of eutherian evolution estimated without assuming a constant rate of molecular evolution. Genes Genet Syst 78: 267-283.

Hedges SB, Poling LL (1999) A molecular phylogeny of reptiles. Science 283: 998-1001.

International Chicken Genome Sequencing Consortium (2004) Sequence and comparative analysis of the chicken genome provide unique perspectives on vertebrate evolution. Nature 432: 695-716.

Iwabe N, Hara Y, Kumazawa Y, Shibamoto K, Saito Y, Miyata T, Katoh K (2005) Sister group relationship of turtles to the bird-crocodilian clade revealed by nuclear DNA-coded proteins. Mol Bio Evol 22: 810-813.

Janke A, Arnason U (1997) The complete mitochondrial genome of Alligator mississippiensis and the separation between recent Archosauria (birds and crocodiles). Mol Biol Evol 14: 1266-1272.

Jones KW, Singh L (1985) Snakes and the evolution of sex chromosomes. Trends Genet 1: 55-61.

King M, Rofe R (1976) Karyotypic variation in the Australian Gekko Phyllodactylus marmoratus (Gray)(Gekkonidae: Reptilia). Chromosoma 54: 75-87.

Kohn M, Kehrer-Sawatzki H, Vogel W, Graves JAM, Hameister H (2004) Wide genome comparisons reveal the origins of the human $\mathrm{X}$ chromosome. Trends Genet 20: 598-603.

Kumar S, Hedges SB (1998) A molecular timescale for vertebrate evolution. Nature 392: 
917-920.

Kumazawa Y, Nishida M (1999) Complete mitochondrial DNA sequences of the green turtle and blue-tailed mole skink: statistical evidence for Archosaurian affinity of turtles. Mol Biol Evol 16: 784-792.

Mannen H, Li SS-L (1999) Molecular evidence for a clade of turtles. Mol Phyl Evol 13: 144-148.

Matsuda Y, Chapman VM (1995) Application of fluorescence in situ hybridization in genome analysis of the mouse. Electrophoresis 16: 261-272.

Mindell DP, Sorenson MD, Dimcheff DE, Hasegawa M, Ast JC, Yuri T (1999) Interordinal relationships of birds and other reptiles based on whole mitochondrial genomes. Syst Biol 48: 138-152.

Nanda I, Shan Z, Schartl M, Burt DW, Koehler M, Nothwang H-G, Grützner F, Paton IR., Windsor D, Dunn I, Engel W, Staeheli P, Mizuno S, Haaf T, Schmid M (1999) 300 million years of conserved synteny between chicken $\mathrm{Z}$ and human chromosome 9 . Nat Genet 21: 258-259.

Nanda I, Zend-Ajusch E, Shan Z, Grützner F, Schartl M, Burt DW, Koehler M, Fowler VM, Goodwin G, Schneider WJ, Mizuno S, Dechant G, Haaf T, Schmid M (2000) Conserved synteny between the chicken $\mathrm{Z}$ sex chromosome and human chromosome 9 includes the male regulatory gene DMRT1: a comparative (re)view on avian sex determination. Cytogenet Cell Genet 89: 67-78.

Pieau C, Dorizzi M (2004) Oestrogens and temperature-dependent sex determination in reptiles: all is in the gonads. $J$ Endocrinol 181: 367-377. 
Pieau C, Dorizzi M, Richard-Mercier N (1999) Temperature-dependent sex determination and gonadal differentiation in reptiles. Cell Mol Life Sci 55: 887-900.

Raymond CS, Shamu CE, Shen MM, Seifert KJ, Hirsch B, Hodgkin J, Zarkower D (1998) Evidence for evolutionary conservation of sex-determing genes. Nature 391: 691-695.

Raymond CS, Parker ED, Kettlewell JR, Brown LG, Page DC, Kusz K, Jaruzelska J, Reinberg Y, Flejter WL, Bardwell VJ, Hirsch B, Zarkower D (1999) A region of human chromosome 9p required for testis development contains two genes related to known sexual regulators. Hum Mol Genet 8: 989-996.

Sarre SD, Georges A, Quinn A (2004) The ends of a continuum: genetic and temperature-dependent sex determination in reptiles. BioEssays 26: 639-645.

Sasaki M, Takagi N, Nishida C (1984) Current profiles of avian cytogenetics, with notes on chromosomal diagnosis of sex in birds. the nucleus 27: 63-73.

Sato H, Ota H (2001) Karyotype of the Chinese soft-shelled turtle, Pelodiscus sinensis, from Japan and Taiwan, with chromosomal data for Dogania subplana. Cur Herpetol 20: 19-25.

Schmid M, Nanda I, Guttenbach M, Steinlein C, Hoehn H, Schartl M, Haaf T, Weigend S, Fries R, Buerstedde J-M, Wimmers K, Burt DW, Smith J, A'Hara S, Law A, Griffin DK, Bumstead N, Kaufman J, Thomson PA, Burke T, Groenen MAM, Crooijmans RPMA, Vignal A, Fillon V, Morisson M, Pitel F, Tixier-Boichard M, Ladjali-Mohammedi K, Hillel J, Mäki-Tanila A, Cheng HH, Delany ME, Burnside J, Mizuno S (2000) First report on chicken genes and chromosomes 2000. 
Cytogenet Cell Genet 90: 169-218.

Shetty S, Griffin DK, Graves JAM (1999) Comparative painting reveals strong chromosome homology over 80 million years of bird evolution. Chromosome Res 7: 289-295.

Shetty S, Kirby P, Zarkower D, Graves JAM (2002) DMRT1 in a ratite bird: evidence for a role in sex determination and discovery of a putative regulatory element. Cytogenet Genome Res 99: 245-251.

Singh L (1972) Evolution of karyotypes in snakes. Chromosoma 38: 185-236.

Smith CA, Sinclair AH (2004) Sex determination: insights from the chicken. BioEssays 26: $120-132$.

Suzuki T, Kurosaki T, Shimada K, Kansaku N, Kuhnlein U, Zadworny D, Agata K, Hashimoto A, Koide M, Koike M, Takata M, Kuroiwa A, Minai S, Namikawa T, Matsuda Y (1975) Cytogenetic mapping of 31 functional genes on chicken chromosomes by direct R-banding FISH. Cytogenet Cell Genet 87: 32-40.

Takagi N, Sasaki MA (1974) Phylogenetic study of bird karyotypes. Chromosoma 46: 91-120.

Wallis JW, Aerts J, Groenen MAM, Crooijmans RPMA, Layman D, Graves TA, Scheer DE, Kremitzki C, Fedele MJ, Mudd NK, Cardenas M, Higginbotham J, Carter J, McGrane R, Gaige T, Mead K, Walker J, Albracht D, Davito J, Yang SP, Leong S, Chinwalla A, Sekhon M, Wylie K, Dodgson J, Romanov MN, Cheng H, de Jong PJ, Osoegawa K, Nefedov M, Zhang H, McPherson JD, Krzywinski M, Schein J, Hillier LD, Mardis ER, Wilson RK, Warren WC (2004) A physical map of the 
chicken genome. Nature 432: 761-764.

Zardoya R, Meyer A (1998) A Complete mitochondrial genome suggests diapsid affinities of turtles. Proc. Natl. Acad. Sci. USA, 95: 14226-14231. 


\section{Figure legends}

Figure 1 Giemsa-stained karyotypes of chicken $(2 n=78)(a)$, the Chinese soft-shelled turtle $(2 n=66)$ (b) and the Japanese four-striped rat snake $(2 n=36)(c)$.

Figure 2 Comparative FISH mapping of EST clones in the Chinese soft-shelled turtle and the Japanese four-striped rat snake. PPP1CC (a), ACTC (c) and SLC20A1 (d) genes are localized to chromosome 1 , chromosome 5 and a pair of microchromosomes in the Chinese soft-shelled turtles, respectively. TUBGCP2 (e) and FLJ12571 (f) genes are localized to chromosome 1 and chromosome 6 in the Japanese four-striped rat snake, respectively. (b) Hoechst-stained chromosomes of the metaphase spread shown in (a), which show the same banding patterns as G-banding. Scale bar indicates $10 \mu \mathrm{m}$. Arrowheads indicate the fluorescence signals.

Figure 3 Comparative chromosome map between chicken and the Chinese soft-shelled turtle. The gene symbols are described following human gene nomenclature. The G-band ideogram of chicken chromosomes was obtained from ARKdb-chick Roslin Institute (http://www.thearkdb.org/browser?species=chicken). The G-band ideogram of the turtle chromosomes was made with Hoechst 33258-stained band patterns obtained by our replication R-banding method. The chromosome homologies between these species were indirectly compared according to the current information on the chicken-human comparative map (Schmid et al. 2000, Burt 2002). The chicken linkage maps are shown between the cytogenetic chromosome maps of chicken and the turtle. The conserved 
regions that are homologous to human chromosomes are represented by the colored boxes on the linkage map. The numeral value on the linkage map indicates map position (cM). The solid lines indicate the locations of the genes finely localized to the conserved subchromosomal regions of human chromosomes. The dotted lines indicate the locations of the turtle genes that are localized to the vicinity of the subchromosomal regions conserved between human and chicken. TRA1 on PSI1 is mapped to both turtle and chicken chromosomes. Chromosome homology to HSA8q where human RPL8 is located has not been identified in GGA1.

Figure 4 Comparative cytogenetic map of the Japanese four-striped rat snake. The G-band ideogram of the snake chromosomes was made according to Hoechst 33258-stained band patterns. The locations of the genes are represented to the right of the snake chromosomes. The human chromosomes with linkage homology to the snake chromosomes are shown to the left of chromosomes. The conserved segments of human chromosomes, to which two or more genes on the same chromosome arm are localized, are show in color. Bars demonstrate the extents of the conserved chromosome segments.

Figure 5 Comparison of the chicken Z chromosome with the Chinese soft-shelled turtle chromosome 6 and the Japanese four-striped rat snake chromosome 2. The linkage map of the chicken $\mathrm{Z}$ chromosome is shown between the cytogenetic chromosome maps of chicken and the turtle. The colored boxes indicate the homology to the respective human chromosomes. The turtle and snake CHD1, ACO1 and DMRT1 genes were cloned as cDNA fragments by RT-PCR. The turtle CHD1 gene was also mapped using its EST 
clone.

Figure 6 Comparison of amino acid sequences of the DMRT1 genes of chicken (Gg), the Chinese soft-shelled turtle (Ps) and the Japanese four-striped rat snake (Eq). The amino acids that are identical between two or three genera are highlighted in green columns. The pink highlighting indicates the DM domain. 
a

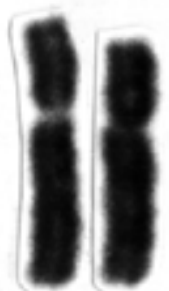

2

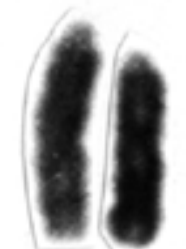

3

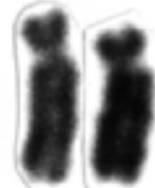

4

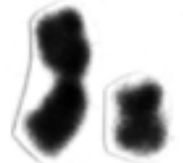

Z W

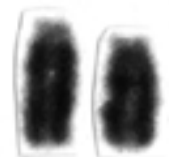

5

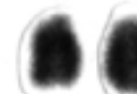

6
6. $\times$

7

8

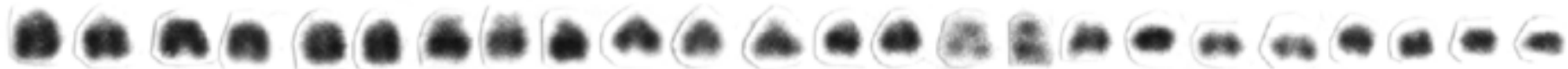

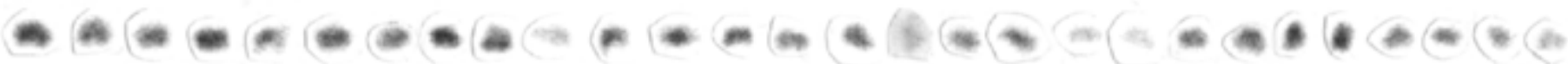

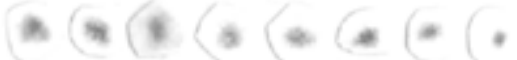
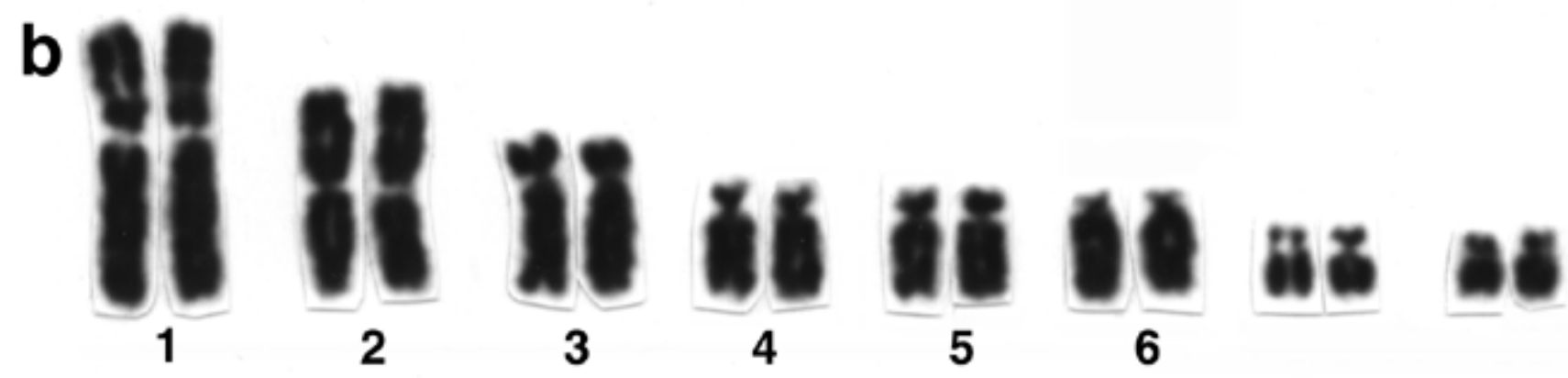

a

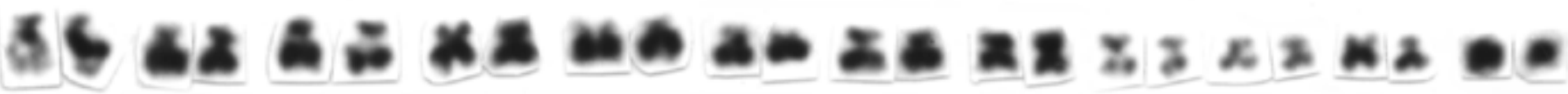

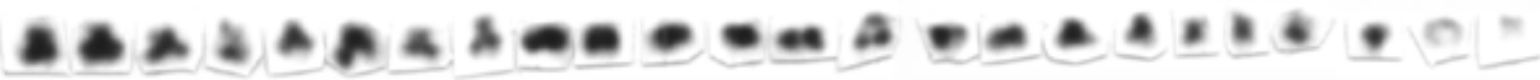
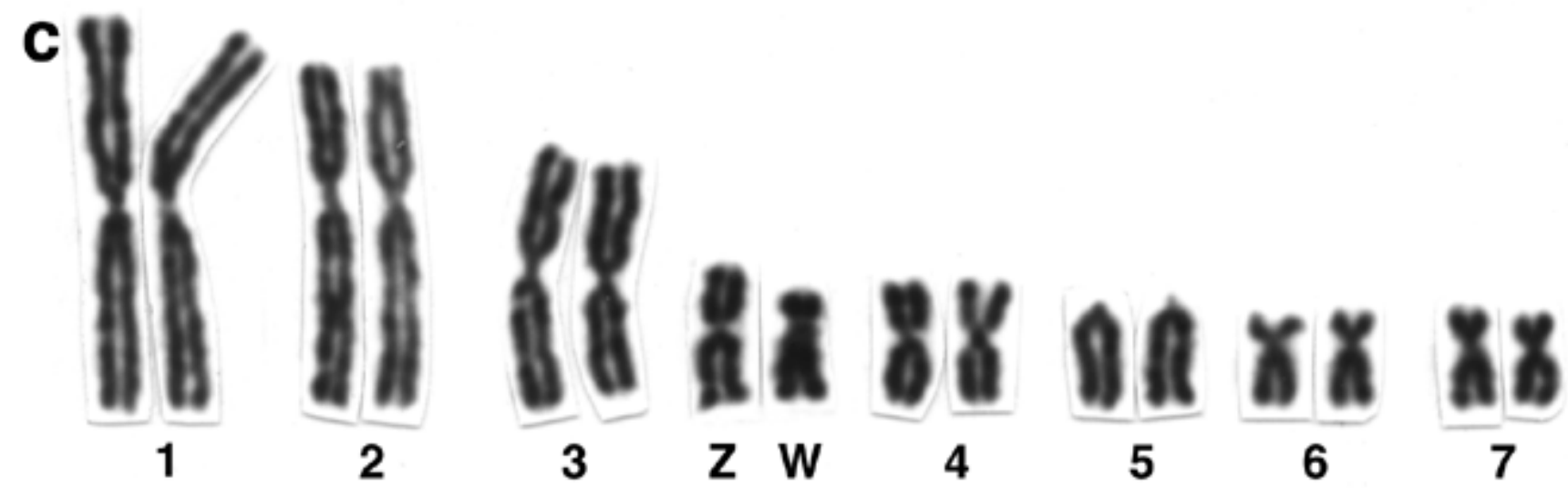

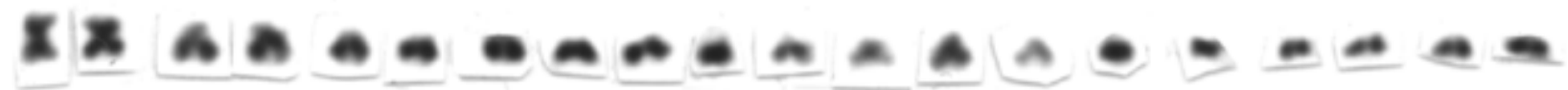

Figure 1 (Matsuda et al.) 


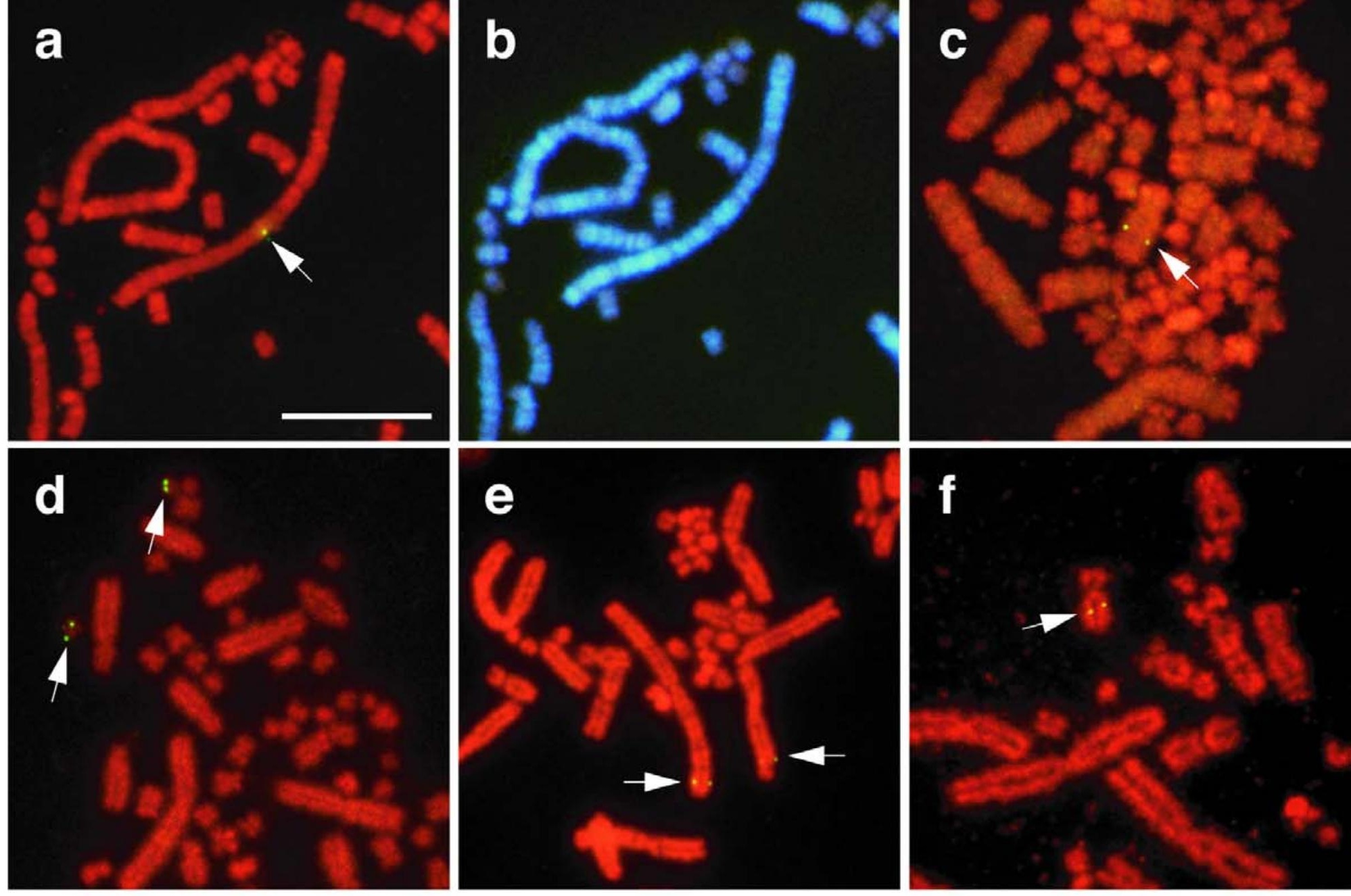

Figure 2 (Matsuda et al.) 

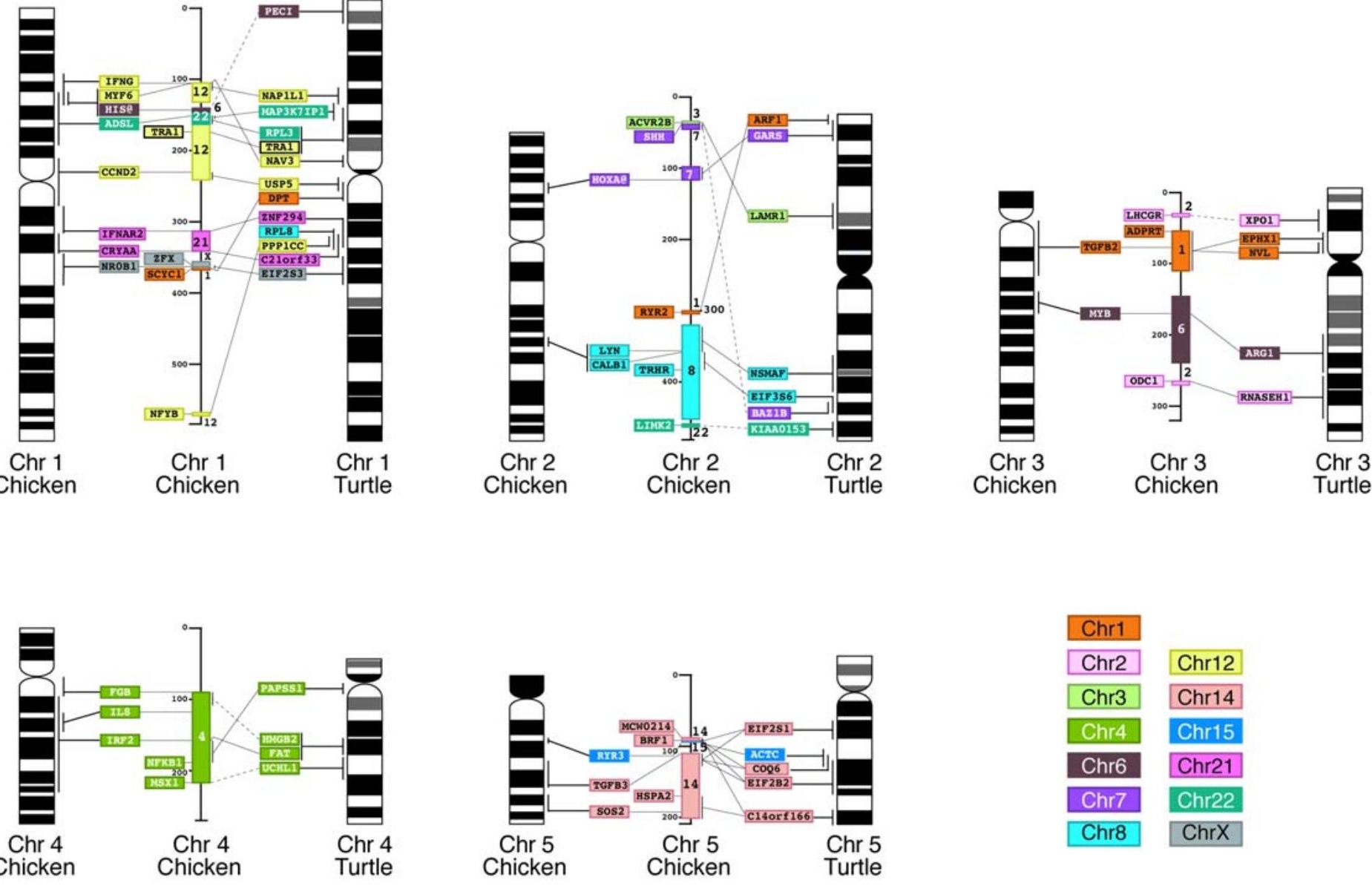

\begin{tabular}{|l|l|}
\hline Chr1 & \\
\hline Chr2 & \\
\hline Chr1 & Chr12 \\
\hline Chr14 \\
\hline Chr4 & Chr15 \\
\hline Chr6 & Chr21 \\
\hline Chr7 & Chr22 \\
\hline Chr8 & ChrX \\
\hline
\end{tabular}

Figure 3 (Matsuda et al.) 


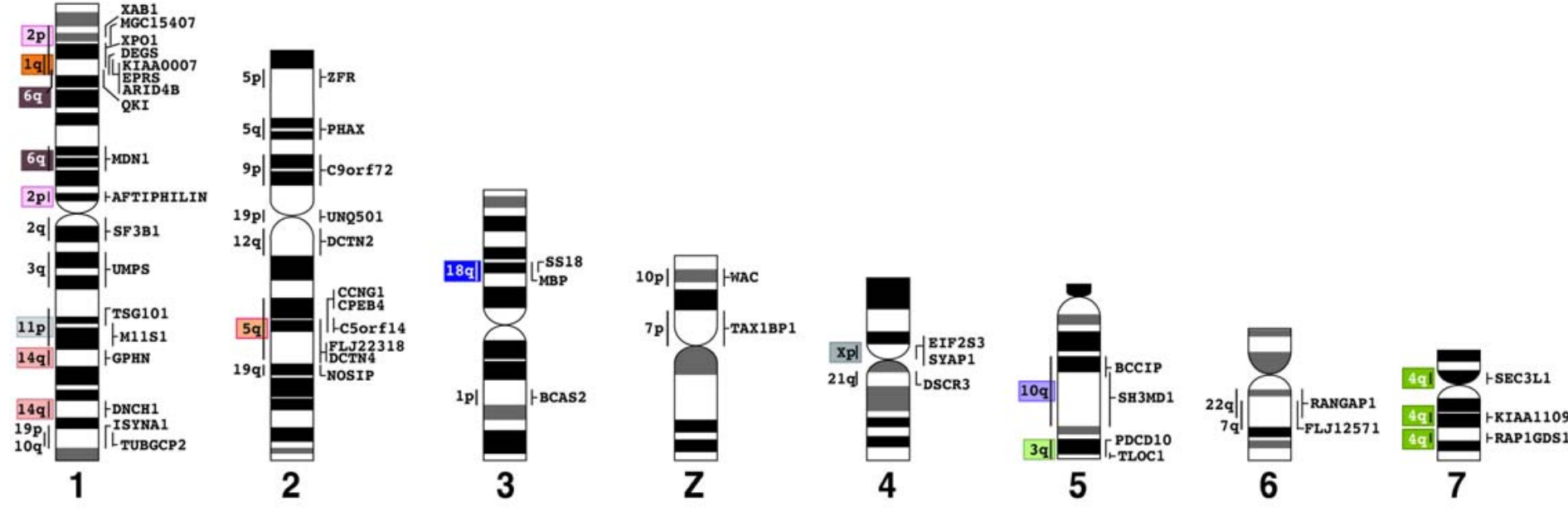

Figure 4 (Matsuda et al.) 
$\mathrm{Gg}$

PS

Eq

$\mathrm{Gg}$

PS

Eq

$\mathrm{Gg}$

PS

Eq

$\mathrm{Gg}$

PS

Eq 150

$\mathrm{Gg}$

148

Ps 199

Eq 199

$\mathrm{Gg}$

198

249

Eq 249

Gg

248

299

$\mathrm{Eq}$

299 50
1

MPNDSSFNKPSASSDHHAQGGKMGSFGKAAVLMTAAAPAGGGG-AAGVLA 1 MPNETSFSKPSASSEHHAQGTKTGPFGKAAGLAAAGGGGNSGGLTQGPAG

1 --PGAGKKLPRLPKCARCRNHGYSSPLKGHKRFCMWRDCQCKKCSLIAER

$P$

GKKSPR

PRLPKC

KCA

RCRNHGYSSPLKGHKRFCMWRDCQCKKCSLIAER 48

99

100

49 QRVMAAQVALRRQQAQEEELGISHPVPLPSAPEPVVKK-SSSSSSCLLQD 97 QRVMAAQVALRRQQAQEEELGISHPIPLPSAPELFVKKENNGGSSCLLLE QRVMAAQVALRRQQAQEEELGISHP IPLPSATEMYVKKENNANSSC-LLE

8 SSSPAHSTSTVAAAAASAPPEGRMLIQDIPSIPSRGHLESTSDLVVDSTY SSSPTHST-NTATTASSTPAEGRMLIODIPSITSRGHLESTSDLVVDSTY STSPPQST-TTATVVSTSSTEGRMLIQDIPSLASRGHLESTSDLVMDPTY

YSSFYQPSLYPYYNNLYNYSQYQMAVATESSSSETGGTFVGSAMKNSLRS YSSFYQPSLYPYYNNLYNYSQYQMAVASESSSSDMGGTLVGSPVKNSLRS YSSLYQPSLYPYYNNLYNYSQYQMAVATETTSGDMGSPLSGSPVKSSLRS

LPATYMSSQSGKQWQMKGMENRHAMSSQYRMCSYYPPTSYLGQGVGSPTC LPATYMSSQSGNQWQMKSTESRHAMSSPYRMHSYYSPASYLGQSVSTPAC 247 298 298

LPTTYMSSQSGNQWQVKSPEGRHSLSSQYRMHSYYPSSSYLGQSVGAPAC

VTQILASEDTPSYSESKARVFSPPSSQDSGLGCLSSSESTKGDLECEPHQ VPQIFTFEDSPSYSESKASVFSPPSSQ--------------------VPQIFTFEENPSYSDTKANVFSPPSSQDSG

$\mathrm{Gg}$

298

EPGAFAVSPVLEGE

311

Ps

Eq 
Table1. The list of 59 EST clones mapped to Chinese soft-shelled turtle chromosomes. Closed boxes indicate conserved syntenies between chicken and the Chinese soft-shelled turtle, which are equivalent between the two species.

\begin{tabular}{|c|c|c|c|c|c|c|c|}
\hline Gene symbol $^{*}$ & $\begin{array}{c}\text { Insert } \\
\text { length }(\mathrm{kb})\end{array}$ & $\begin{array}{l}\text { Sequence } \\
\text { length }\end{array}$ & $\begin{array}{c}\text { E- } \\
\text { value }\end{array}$ & $\begin{array}{c}\text { Chromosome } \\
\text { location in human }\end{array}$ & $\begin{array}{l}\text { Chromosome } \\
\text { location in the }\end{array}$ & $\begin{array}{l}\text { Chromosome } \\
\text { location in }\end{array}$ & $\begin{array}{c}\text { Accession } \\
\text { Number }\end{array}$ \\
\hline PECI & 2.0 & 809 & $\mathrm{e}-105$ & $6 \mathrm{p} 24.3$ & $1 p$ & & AU312267 \\
\hline NAV3 & 1.2 & 1033 & e-123 & $12 q 14.3$ & $1 p$ & 1 & AU312263 \\
\hline NAP1L1 & 2.0 & 811 & $2 e-90$ & 12q21.1 & $1 \mathrm{p}$ & 1 & AU312281 \\
\hline TRA1 & 2.5 & 531 & $2 e-84$ & $12 \mathrm{q} 24.2-\mathrm{q} 24.3$ & $1 \mathrm{p}$ & 1 & AU312248 \\
\hline RPL3 & 1.6 & 498 & $1 e-95$ & $22 \mathrm{q} 13$ & $1 \mathrm{p}$ & 1 & AU312265 \\
\hline MAP3K7IP1 & 1.0 & 561 & 3e-78 & 22q13.1 & $1 \mathrm{p}$ & 1 & AU312271 \\
\hline DPT & 1.2 & 680 & $1 e-79$ & $1 q 12-q 23$ & $1 q$ & & AU312278 \\
\hline RPL8 & 1.0 & 824 & e-148 & $8 q 24.3$ & $1 \mathrm{q}$ & & AU312288 \\
\hline USP5 & 1.2 & 800 & e-106 & $12 \mathrm{p} 13$ & $1 \mathrm{q}$ & 1 & AU312276 \\
\hline PPP1CC & 2.5 & 519 & $3 e-64$ & $12 \mathrm{q} 24.1-\mathrm{q} 24.2$ & $1 q$ & 15 & AU312244 \\
\hline ZNF294 & 2.0 & 543 & $4 e-71$ & $21 q 22.11$ & $1 q$ & 1 & AU312299 \\
\hline C21orf33 & 2.5 & 655 & e-113 & $21 \mathrm{q} 22.3$ & $1 \mathrm{q}$ & 1 & AU312295 \\
\hline EIF2S3 & 2.0 & 658 & e-134 & Xp22.2-p22.1 & $1 q$ & 1 & AU312268 \\
\hline ARF1 & 2.0 & 649 & 2e-96 & $1 q 42$ & $\frac{1}{2 p}$ & 2 & AU312289 \\
\hline LAMR1 & 1.0 & 829 & e-129 & 3p21.3 & $2 \mathrm{p}$ & & AU312259 \\
\hline GARS & 2.0 & 802 & e-162 & $7 p 15$ & $\frac{2 p}{2 p}$ & 2 & AU312286 \\
\hline BAZ1B & 2.0 & 756 & 3e-97 & $7 q 11.23$ & $\frac{r}{2 q}$ & 19 & AU312277 \\
\hline NSMAF & 4.0 & 521 & $5 e-97$ & $8 q 12-q 13$ & $2 q$ & 2 & AU312241 \\
\hline EIF3S6 & 1.6 & 548 & e-110 & $8 q 22-q 23$ & $2 q$ & 2 & AU312274 \\
\hline KIAA0153 & 1.8 & 809 & $7 e-49$ & $22 q 13.31$ & $\frac{-1}{2 q}$ & & AU312266 \\
\hline NVL & 2.0 & 794 & e-101 & $1 q 41-q 42.2$ & $3 p$ & 3 & AU312294 \\
\hline EPHX1 & 1.7 & 737 & $4 e-79$ & $1 q 42.1$ & $3 p$ & 3 & AU312282 \\
\hline XPO1 & 2.3 & 573 & e-124 & 2p16 & $3 p$ & 3 & AU312293 \\
\hline RNASEH1 & 3.0 & 520 & $5 e-70$ & 2p25 & $3 q$ & 3 & AU312243 \\
\hline ARG1 & 1.2 & 760 & $5 e-87$ & $6 q 23$ & $3 q$ & & AU312300 \\
\hline UCHL1 & 3.0 & 532 & $4 e-77$ & $4 \mathrm{p} 14$ & $4 q$ & 4 & AU312247 \\
\hline PAPSS1 & 1.5 & 810 & e-166 & $4 q 24$ & $4 \mathrm{q}$ & 4 & AU312290 \\
\hline HMGB2 & 1.8 & 901 & $2 e-90$ & $4 q 31$ & $4 q$ & 4 & AU312262 \\
\hline FAT & 2.1 & 527 & $e-100$ & 4q34-q35 & $4 q$ & 4 & AU312273 \\
\hline C14orf166 & 1.0 & 687 & $4 e-95$ & $14 q 22.1$ & $5 q$ & 5 & AU312301 \\
\hline EIF2S1 & 1.5 & 461 & $6 e-73$ & $14 q 24.1$ & $5 q$ & 5 & AU312298 \\
\hline COQ6 & 1.0 & 925 & $9 e-66$ & $14 q 24.2$ & $5 q$ & 5 & AU312260 \\
\hline EIF2B2 & 2.1 & 839 & e-108 & $14 q 24.3$ & $5 q$ & 5 & AU312297 \\
\hline ACTC & 1.5 & 739 & e-148 & 15q11-q14 & $5 q$ & 5 & AU312292 \\
\hline CLTA & 1.0 & 799 & 3e-96 & $9 p 13$ & $6 \mathrm{p}$ & $\mathrm{Z}$ & AU312285 \\
\hline CHD1 & 2.0 & 798 & $5 e-92$ & 5q15-q21 & $6 q$ & & AU312270 \\
\hline ALDH7A1 & 1.7 & 616 & $2 e-84$ & $5 q 31$ & $6 q$ & unknown & AU312269 \\
\hline FBP1 & 1.5 & 732 & e-134 & 9q22.3 & $6 q$ & $\mathrm{z}$ & AU312291 \\
\hline CDK9 & 1.5 & 275 & $5 e-45$ & 9q34.1 & $6 q$ & & AU312239 \\
\hline SIAT8C & 1.4 & 420 & $1 e-86$ & $18 q 21.31$ & $6 q$ & & AU312252 \\
\hline SLC20A1 & 3.0 & 740 & $2 e-48$ & $2 q 11-q 14$ & micro & & AU312245 \\
\hline SCG2 & 2.3 & 636 & $2 e-53$ & 2q35-q36 & micro & 9 & AU312275 \\
\hline RASA2 & 3.0 & 561 & $3 e-67$ & $3 q 22-q 23$ & micro & 9 & AU312254 \\
\hline PLD1 & 3.0 & 517 & e-102 & $3 q 26$ & micro & 9 & AU312251 \\
\hline HNRPD & 1.5 & 504 & $2 e-87$ & 4q21.1-q21.2 & micro & & AU312284 \\
\hline CTNNA1 & 4.5 & 520 & $5 e-88$ & $5 q 31$ & micro & 13 & AU312240 \\
\hline SKP1A & 1.8 & 815 & $8 e-95$ & $5 q 31$ & micro & & AU312280 \\
\hline SPARC & 2.0 & 513 & $2 e-65$ & 5q31.3-q32 & micro & 13 & AU312255 \\
\hline CSNK1A1 & 2.0 & 449 & $5 e-73$ & $5 q 32$ & micro & 13 & AU312296 \\
\hline GTF2I & 2.0 & 761 & $1 e-90$ & $7 q 11.23$ & micro & 19 & AU312279 \\
\hline PTN & 2.2 & 516 & $4 e-71$ & 7q33-q34 & micro & 1 & AU312250 \\
\hline LHX2 & 1.5 & 710 & e-129 & $9 q 33-34.1$ & micro & 17 & AU312297 \\
\hline COX15 & 1.2 & 519 & $3 e-81$ & $10 q 24$ & micro & 6 & AU312249 \\
\hline KARS & 1.5 & 516 & e-106 & 16q23-q24 & micro & 11 & AU312242 \\
\hline EEF2 & 1.2 & 526 & $2 e-98$ & 19pter-q12 & micro & 28 & AU312258 \\
\hline EEF1A2 & 2.0 & 513 & 3e-86 & $20 q 13.3$ & micro & 20 & AU312256 \\
\hline ТОРЗВ & 1.8 & 804 & e-118 & $22 q 11.22$ & micro & 15 & AU312272 \\
\hline COL4A5 & 2.2 & 795 & e-112 & Xq22 & micro & 4 & AU312283 \\
\hline DCX & 1.7 & 1125 & e-107 & Xq22.3-q23 & micro & 4 & AU312264 \\
\hline
\end{tabular}

*Human gene symbol

Unknown: The nucleotide sequence of the gene is annotated in the chicken genome sequence but its chromosomal location is not still identified. 
Table 2. The list of 52 EST clones mapped to Japanese four-striped rat snake chromosomes.

\begin{tabular}{|c|c|c|c|c|c|c|c|}
\hline Gene symbol ${ }^{*}$ & $\begin{array}{c}\text { Insert } \\
\text { length }(\mathrm{kb})\end{array}$ & $\begin{array}{l}\text { Sequence } \\
\text { length } \\
\text { (bp) }\end{array}$ & $\begin{array}{c}\text { E- } \\
\text { value }\end{array}$ & $\begin{array}{l}\text { Chromosome } \\
\text { location in human }\end{array}$ & $\begin{array}{c}\text { Chromosome } \\
\text { location in the } \\
\text { snake }\end{array}$ & $\begin{array}{c}\text { Chromosome } \\
\text { location in } \\
\text { chicken }\end{array}$ & $\begin{array}{c}\text { Accession } \\
\text { Number }\end{array}$ \\
\hline EPRS & 1.8 & 749 & e-112 & $1 q 41-q 42$ & $1 \mathrm{p}$ & 3 & AU312324 \\
\hline ARID4B & 1.6 & 690 & $3 e-54$ & $1 q 42.1-q 43$ & $1 \mathrm{p}$ & & AU312346 \\
\hline DEGS & 1.4 & 694 & e-101 & $1 \mathrm{~g} 42.12$ & $1 \mathrm{p}$ & unknown & AU312341 \\
\hline AFTIPHILIN & 1.8 & 514 & $5 e-70$ & 2p15 & $1 \mathrm{p}$ & & AU312311 \\
\hline XPO1 & 2.0 & 775 & e-155 & $2 \mathrm{p} 16$ & $1 \mathrm{p}$ & 3 & AU312325 \\
\hline MGC15407 & 1.5 & 716 & $2 \mathrm{e}-70$ & $2 \mathrm{p} 16.2$ & $1 \mathrm{p}$ & 3 & AU312344 \\
\hline KIAA0007 & 2.3 & 418 & $8 e-72$ & $2 \mathrm{p} 23.3$ & $1 \mathrm{p}$ & & AU312332 \\
\hline XAB1 & 1.2 & 767 & $8 e-67$ & $2 \mathrm{p} 23.3$ & $1 \mathrm{p}$ & & AU312353 \\
\hline MDN1 & 2.4 & 679 & $2 e-92$ & $6 q 15$ & $1 \mathrm{p}$ & 3 & AU312339 \\
\hline QKI & 1.8 & 772 & $1 e-50$ & 6q26-q27 & $1 \mathrm{p}$ & 3 & AU312356 \\
\hline SF3B1 & 1.2 & 651 & e-115 & $2 \mathrm{q} 33.1$ & $1 q$ & & AU312337 \\
\hline UMPS & 2.4 & 566 & $1 e-87$ & $3 q 13$ & $1 \mathrm{q}$ & & AU312331 \\
\hline TUBGCP2 & 1.6 & 702 & $\mathrm{e}-101$ & $10 \mathrm{q} 26.3$ & $1 \mathrm{q}$ & & AU312343 \\
\hline M11S1 & 1.8 & 592 & $1 e-53$ & $11 \mathrm{p} 13$ & $1 \mathrm{q}$ & & AU312350 \\
\hline TSG101 & 1.8 & 727 & $7 e-60$ & $11 \mathrm{p} 15$ & $1 \mathrm{q}$ & unknown & AU312316 \\
\hline GPHN & 1.2 & 729 & $7 e-82$ & $14 q 23.3-q 24.1$ & $1 \mathrm{q}$ & 5 & AU312327 \\
\hline DNCH1 & 1.2 & 745 & 1e-85 & 14q32.3-qter & $1 q$ & 5 & AU312310 \\
\hline ISYNA1 & 1.8 & 731 & $1 e-54$ & 19p13.11 & $1 \mathrm{q}$ & 5 & AU312338 \\
\hline ZFR & 1.8 & 738 & e-100 & $5 \mathrm{p} 13.3$ & $2 p$ & & AU312309 \\
\hline PHAX & 2.2 & 760 & $4 \mathrm{e}-71$ & $5 q 23.3$ & $2 p$ & & AU312322 \\
\hline C9orf72 & 3.0 & 727 & e-143 & $9 p 21.1$ & $2 p$ & $\mathrm{z}$ & AU312326 \\
\hline UNQ501 & 1.3 & 746 & $1 e-56$ & $19 \mathrm{p} 13.2$ & 2cen & & AU312305 \\
\hline CPEB4 & 1.8 & 655 & $2 e-74$ & $5 q 21$ & $2 q$ & & AU312333 \\
\hline DCTN4 & 2.3 & 671 & $1 \mathrm{e}-91$ & $5 q 31-q 32$ & $2 q$ & 13 & AU312349 \\
\hline C5orf14 & 1.8 & 730 & $2 e-57$ & $5 q 31.2$ & $2 q$ & unknown & AU312304 \\
\hline CCNG1 & 3.0 & 734 & $5 e-74$ & 5q32-q34 & $2 q$ & 13 & AU312308 \\
\hline FLJ22318 & 1.8 & 780 & $9 e-98$ & $5 q 35.3$ & $2 q$ & & AU312329 \\
\hline DCTN2 & 1.8 & 765 & e-117 & 12q13.2-q13.3 & $2 q$ & & AU312317 \\
\hline NOSIP & 1.5 & 690 & $1 e-60$ & $19 q 13.33$ & $2 q$ & & AU312303 \\
\hline SS18 & 2.5 & 599 & $9 e-92$ & $18 q 11.2$ & $3 p$ & 2 & AU312302 \\
\hline MBP & 2.1 & 757 & $1 \mathrm{e}-44$ & $18 q 23$ & $3 p$ & 2 & AU312318 \\
\hline BCAS2 & 1.3 & 839 & $3 e-87$ & 1p21-p13.3 & $3 q$ & 26 & AU312354 \\
\hline EIF2S3 & 1.8 & 735 & e-157 & Xp22.2-p22.1 & $4 p$ & 1 & AU312306 \\
\hline SYAP1 & 1.5 & 761 & $1 \mathrm{e}-98$ & Xp22.22 & $4 p$ & 1 & AU312328 \\
\hline DSCR3 & 1.8 & 590 & $2 e-98$ & $21 q 22.2$ & $4 q$ & 1 & AU312319 \\
\hline PDCD10 & 1.3 & 791 & $7 e-62$ & $3 q 26.2$ & $5 q$ & 9 & AU312342 \\
\hline TLOC1 & 1.8 & 615 & $7 e-70$ & $3 q 26.2-q 27$ & $5 q$ & 9 & AU312335 \\
\hline SH3MD1 & 2.3 & 764 & $4 e-54$ & $10 q 25.1$ & $5 q$ & 6 & AU312347 \\
\hline BCCIP & 1.8 & 601 & $5 e-56$ & 10q26.1 & $5 q$ & unknown & AU312307 \\
\hline FLJ12571 & 2.3 & 738 & $3 e-66$ & $7 q 34$ & $6 q$ & & AU312352 \\
\hline RANGAP1 & 1.5 & 756 & $9 e-70$ & $22 q 13$ & $6 q$ & 1 & AU312313 \\
\hline SEC3L1 & 2.0 & 711 & $1 \mathrm{e}-63$ & $4 q 12$ & $7 p$ & & AU312345 \\
\hline RAP1GDS1 & 1.3 & 702 & e-118 & 4q23-q25 & $7 q$ & 4 & AU312351 \\
\hline KIAA1109 & 2.0 & 782 & $1 \mathrm{e}-73$ & $4 q 28.1$ & $7 q$ & 4 & AU312348 \\
\hline ASB6 & 1.0 & 675 & $1 e-53$ & 9 & micro & 17 & AU312340 \\
\hline FLJ25530 & 1.1 & 786 & $5 e-86$ & $11 q 24.2$ & micro & & AU312336 \\
\hline GLCE & 2.5 & 431 & $6 e-87$ & $15 q 22.31$ & micro & 10 & AU312330 \\
\hline
\end{tabular}

